\title{
The use of a muscle relaxant to supplement local anaesthetics for Bier's blocks
}

\author{
R. MCGLONE, ${ }^{1}$ F. HEYES ${ }^{2}$ \& P. HARRIS ${ }^{3}$ \\ ${ }^{1}$ The General Infirmary, Leeds, ${ }^{2}$ Accident and Emergency Unit, Hull Royal Infirmary, \\ Hull, and ${ }^{3}$ Department of Anaesthetics, Derbyshire Royal Infirmary, Derby, England
}

\section{SUMMARY}

In searching for the 'ideal' muscle relaxant for use with intravenous regional anaesthesia, muscle relaxation was assessed with and without the addition of Atracurium to Bier's Block in four volunteers. This was followed by a clinical study of 36 patients with wrist fractures to confirm the drug's safety and examine the possible clinical advantages of using a muscle relaxant. The addition of $2 \mathrm{mg}$ of Atracurium to the Bier's Block improved the ease of reduction $(P<0.025)$ and the quality of analgesia $(P<0.05)$ (Mann-Whitney $U$ test). The authors conclude that the addition of Atracurium to a Bier's Block is useful in selected patients with a wrist fracture.

\section{INTRODUCTION}

It is stated in a leading accident and emergency textbook (Wilson \& Flowers, 1986) that young adults with wrist fractures may need a general anaesthetic for adequate muscle relaxation prior to reduction. The Bier's Block technique provides poor muscle relaxation. However, the addition of a small amount of muscle relaxant has been shown to provide good relaxation in the limb (Torda \& Klonymus, 1967; Prippenau, 1985).

The ideal muscle relaxant would have a short half-life, perhaps degrading during the procedure prior to the cuff being released.

Atracurium (Hughes \& Chapple, 1981), the drug the authors decided to investigate, provides full neuromuscular block for 15 to $35 \mathrm{~min}$ only. It is a non-depolarising agent with two metabolic pathways:

(1) enzymic ester hydrolysis; and

(2) Hofmann degradation: under mild alkaline conditions fission occurs at the quarternary nitrogen to laudanosine (the metabolites are inactive). 


\section{PILOT STUDY}

\section{METHOD}

Initial experiments were carried out in four healthy volunteers with no evidence of neuromuscular disorder or sensitivity to local anaesthetics. In each individual, a Bier's Block was performed on two occasions, once with Atracurium added to the local anaesthetic and once without. The drugs and dosages employed are shown below:

(1) lignocaine $0.5 \% 40 \mathrm{ml} \mp$ Atracurium $2 \mathrm{mg}$

(2) Prilocaine $0.5 \% 40 \mathrm{ml} \mp$ Atracurium $1 \mathrm{mg}$

(3) Prilocaine $0.5 \% 40 \mathrm{ml} \mp$ Atracurium $2 \mathrm{mg}$

(4) Prilocaine $0.5 \% 40 \mathrm{ml} \mp$ Atracurium $4 \mathrm{mg}$

The non-dominant arm was used for the procedure. Pressure was applied over the brachial artery and the arm elevated for $3 \mathrm{~min}$ prior to the inflation of the cuff to at least $100 \mathrm{mmHg}$ above the systolic blood pressure. The cuff was kept inflated for at least $20 \mathrm{~min}$.

The effectiveness of the neuromuscular blockade achieved by the various drug combinations was monitored with a Relaxograph. This device utilizes a pair of stimulating electrodes, placed over the ulnar nerve at the wrist, and a pair of recording electrodes, placed over the hypothenar muscles to provide a record of the integrated EMG response to a standardized supramaximal train-of-four stimulus. Typical outputs are shown in Fig. 1.

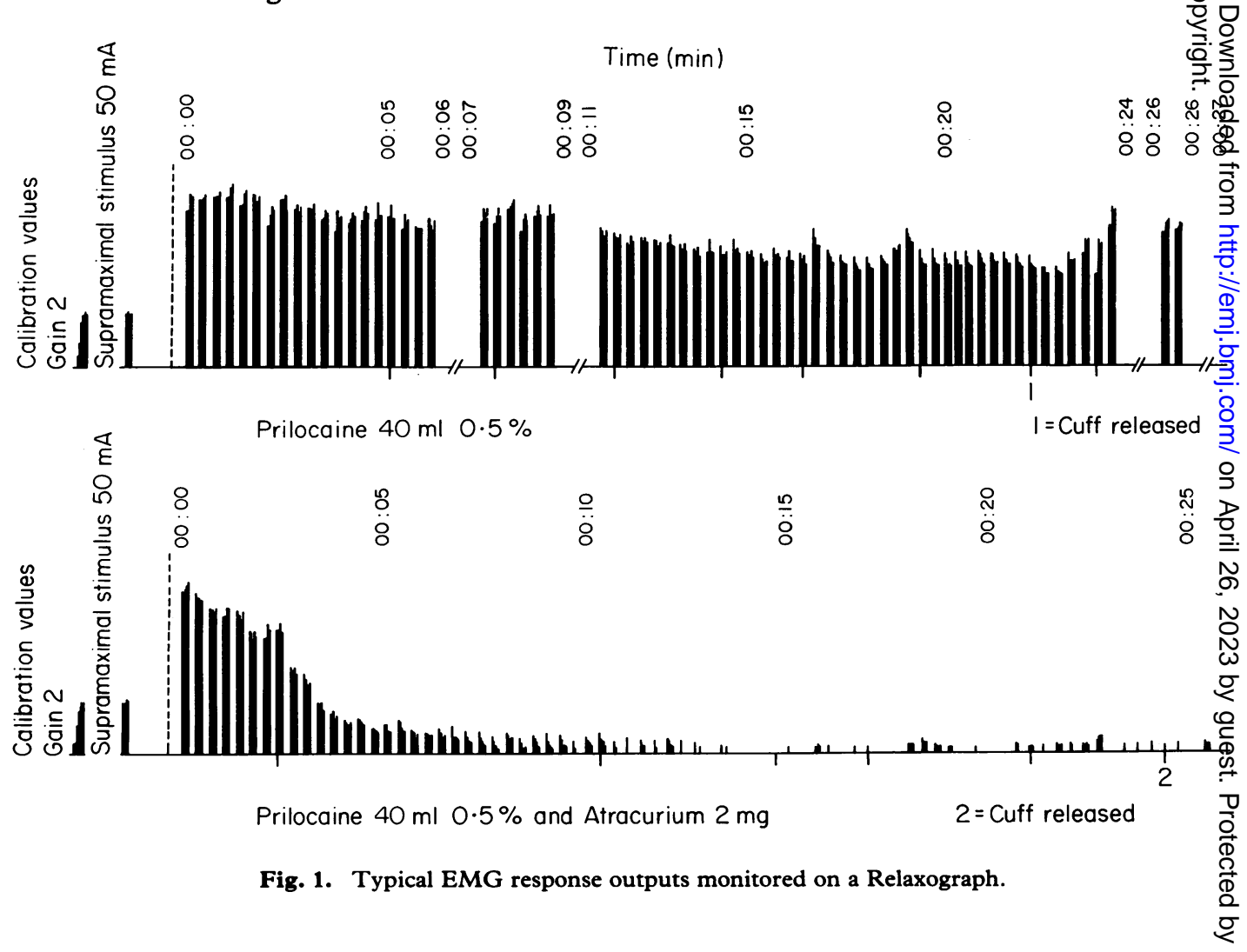


Table 1 Atracurium group

\begin{tabular}{llrl}
\hline & \multicolumn{3}{c}{$\begin{array}{l}\text { Interval (min) following cuff } \\
\text { deflation until: }\end{array}$} \\
\cline { 3 - 4 } $\begin{array}{l}\text { Drug } \\
\text { combination }\end{array}$ & $\begin{array}{l}\text { Cuff } \\
\text { inflation time } \\
(\text { min) }\end{array}$ & $\begin{array}{l}\text { return to 50\% } \\
\text { response to stimulation }\end{array}$ & $\begin{array}{l}\text { return of } \\
\text { fine movement }\end{array}$ \\
\hline (a) & 23 & 7 & 30 \\
(b) & 23 & 23 & 35 \\
(c) & 24 & 9 & 21 \\
(d) & 25 & 67 & 70 \\
\hline
\end{tabular}

Table 2 Local anaesthetic only group

\begin{tabular}{|c|c|c|c|}
\hline \multirow[b]{2}{*}{$\begin{array}{l}\text { Drug } \\
\text { combination }\end{array}$} & \multirow[b]{2}{*}{$\begin{array}{l}\text { Cuff } \\
\text { inflation time } \\
\text { (min) }\end{array}$} & \multicolumn{2}{|l|}{$\begin{array}{l}\text { Interval (min) following } \\
\text { cuff deflation until: }\end{array}$} \\
\hline & & $\begin{array}{l}\text { return of } 50 \% \\
\text { response to stimulation }\end{array}$ & $\begin{array}{l}\text { return of } \\
\text { fine movement }\end{array}$ \\
\hline (a) & 26 & maintained ${ }^{*}$ & 4 \\
\hline (b) & 24 & maintained ${ }^{*}$ & 5 \\
\hline (c) & 22 & maintained* & maintained ${ }^{*}$ \\
\hline (d) & 27 & maintained* & 6 \\
\hline
\end{tabular}

${ }^{*}$ Maintained during procedure.

\section{RESULTS}

The results are shown in Tables 1 and 2 .

Return of fine movement in the hand following the procedure was considered present once thumb to fingers opposition could be performed in quick succession.

From the above results, it can be seen that the time to return of a $50 \%$ response to stimulation is only an approximate guide to the return of motor function.

Volunteer (c) developed a sensory radial nerve palsy which resolved after $6 \mathrm{~h}$. Volunteer (d) was aware of difficulty with focusing lasting $5 \mathrm{~min}$ when the cuff was released. (The solution contained $4 \mathrm{mg}$ Atracurium.)

\section{DISCUSSION}

The delay in return of muscle function ( $70 \mathrm{~min}$ ) and the 'diplopia' experienced by case (d) suggest that the muscle relaxant did not degrade in the ischaemic limb.

The evidence in the literature is conflicting. In a case report by Alegesan (1983), an 
18-month-old baby was undergoing an operation for pes cavus with a general anaesthetic using Atracurium $0.3 \mathrm{mg} / \mathrm{kg}$. Ten minutes following inflation of the tourniquet the limb was observed to move. The author postulated that the Atracurium had broken down in the limb.

Suppan (1983) in a report of 10 patients all undergoing a general anaesthetic using Atracurium, with a tourniquet applied to a limb for a bloodless field, stated that limb movements had not been observed in any of them, the tourniquet time ranging from 35 to $120 \mathrm{~min}$. The author concluded that Hofmann degeneration was inhibited in an ischaemic limb due to the metabolic acidosis and/or Atracurium is dependant on muscle blood flow for its termination of action.

To confirm that there was no significant degradation of Atracurium in an ischaemic limb, a surgical procedure (excision of radial head) was performed under a Bier's Block using Prilocaine $0.5 \% 40 \mathrm{ml}$ and Atracurium $2 \mathrm{mg}$ with Relaxograph monitoring (see Fig. 2). There was no response to stimulation till $53 \mathrm{~min}$ after the cuff was deflated (cuff time $47 \mathrm{~min}$ ). Thus, Atracurium does not break down in the ischaemic limb.
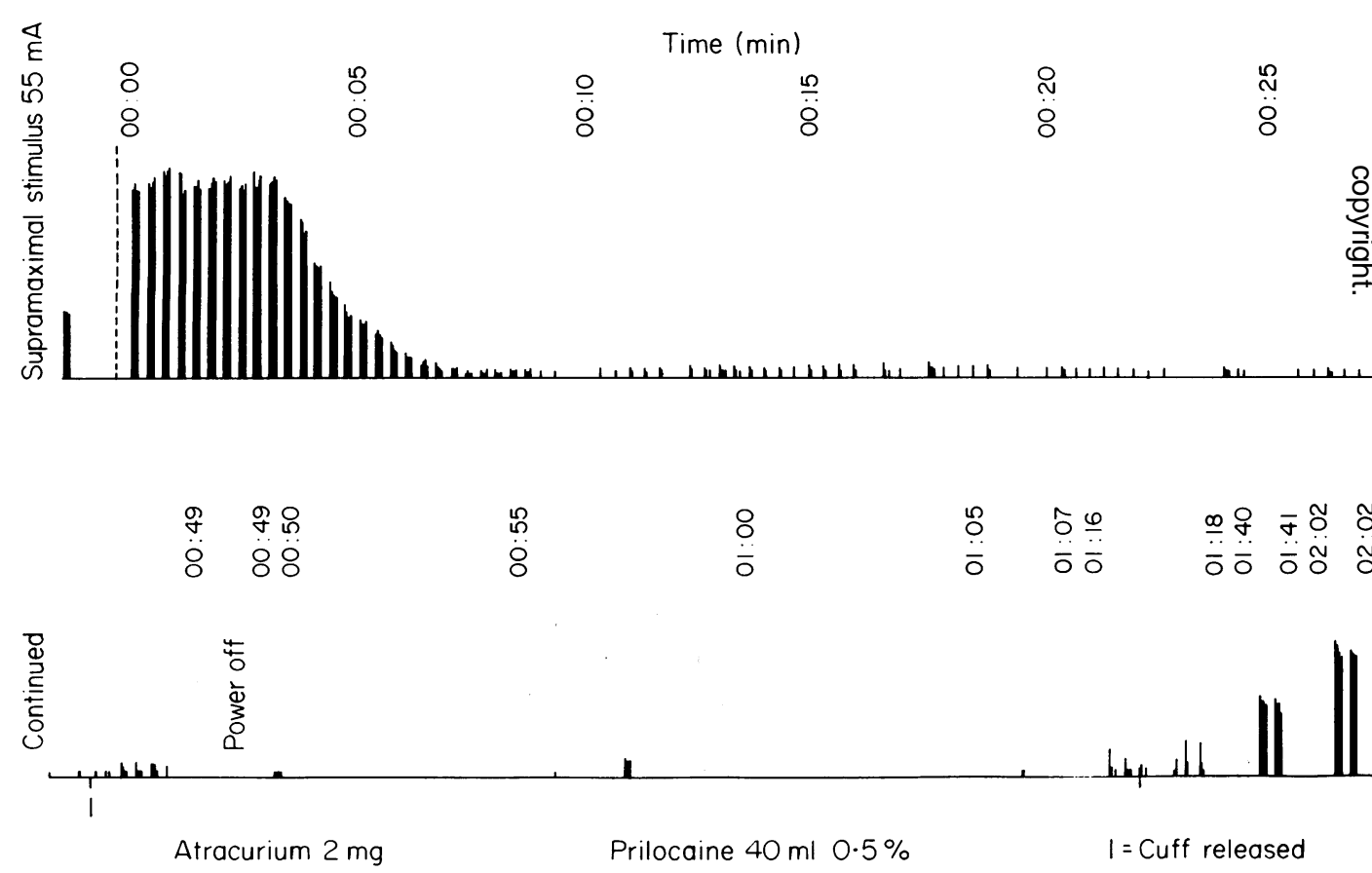

Fig. 2. Relaxograph monitoring of excision of radial head under a Bier's block using Prilocaine 0.5\% $40 \mathrm{ml}$ and Atracurium $2 \mathrm{mg}$. 


\section{CLINICAL STUDY}

\section{METHOD}

To investigate the clinical use of Atracurium, patients below the age of 55 years presenting to the department with wrist fractures were randomly allocated to two groups, receiving either:

(1) Prilocaine $0.5 \% 40 \mathrm{ml}$; or

(2) Prilocaine $0.5 \% 40 \mathrm{ml}+$ Atracurium $2 \mathrm{mg}$.

The reductions were done by either a registrar or a senior registrar, the operator being unaware of the group to which the patient had been allocated.

The affected limb was elevated for 3 min with pressure over the brachial artery prior to inflation of the cuff to at least $100 \mathrm{mmHg}$ above systolic blood pressure. Reduction was attempted $10 \mathrm{~min}$ after injection.

There were two postulates: that reduction would be (1) easier and (2) less painful using a muscle relaxant.

Following reduction, the operator assessed the ease of reduction on a visual analogue scale $0-10$. The angle of fracture displacement was noted and the post-reduction film categorized as unacceptable, acceptable or good/anatomical.

The patient was questioned about pain at rest; pain at rest $10 \mathrm{~min}$ after injection and pain during reduction, again using a visual analogue scale $0-10$. The patient was also directly questioned about dysaesthesia, diplopia and return of fine motor control noted after cuff deflation. The operator was only then informed of which solution had been used.

There were 18 patients in the Prilocaine Group A (five male and 13 female) and 18 patients in the Atracurium Group B (six male and 12 female).

\section{RESULTS}

There was no significant difference in age or angle of fracture between Groups A and B (see Table 3).

Predictably, return of fine motor control was delayed in Group B $25.8 \mathrm{~min}$ (range 12$45 \mathrm{~min}$ ) compared with Group A 4.8 min (range 1-20 min): $P<0.001$ (Mann-Whitney U-test).

Only three patients in Group B experienced transient difficulty with focusing when the cuff was released. No dysaesthesia was noted.

There was a demonstrable difference between the groups in pain relief during reduction $(P<0.05)$ when comparing the ease of reduction, Group $B$ reductions were significantly easier $(P<0.025)$. In subject AG in Group A (male $86 \mathrm{~kg}$ ), the initial plain Prilocaine block failed due to lack of relaxation as the distal fragment was overlapping. Reduction was later achieved using a Prilocaine and Atracurium Bier's Block (see Table 3). In subject $\mathrm{GS}$ (Group $A$; male $80 \mathrm{~kg}$ ) the reduction failed at $10 \mathrm{~min}$ but was repeated with difficulty at $15 \mathrm{~min}$ with an acceptable result. 
Table 3 Results of the clinical study

\begin{tabular}{|c|c|c|c|c|c|}
\hline & \multicolumn{2}{|c|}{$\begin{array}{l}\text { Group A } \\
\text { (Prilocaine } \\
\text { only; } \\
n+18)\end{array}$} & \multicolumn{2}{|c|}{$\begin{array}{l}\text { Group B } \\
\text { (Prilocaine and } \\
\text { Atracurium; } \\
n=18 \text { ) }\end{array}$} & \multirow[t]{2}{*}{$\begin{array}{l}\text { Significance of } \\
\text { difference between } \\
\text { means }\end{array}$} \\
\hline & Range & Mean & Range & Mean & \\
\hline $\begin{array}{l}\text { Ease of reduction } \\
(0=\text { impossible; } \\
10=\text { very easy })\end{array}$ & $0-10$ & 6 & $3-10$ & $8 \cdot 4$ & $p<0.025$ \\
\hline $\begin{array}{l}\text { Time to return of fine } \\
\text { movement (min) }\end{array}$ & $1-20$ & $4 \cdot 8$ & $12-45$ & $25 \cdot 8$ & $p<0.001$ \\
\hline
\end{tabular}

Pain scores

( $0=$ painless; 10 worst pain

imaginable):

Prior to injection

$10 \mathrm{~min}$ after injection

During reduction

$1-8$

$4 \cdot 1$

1-10

$4 \cdot 8$

N.S*

0-2 $\quad 0.5$

0-2 $\quad 0.5$

$\begin{array}{lllll}0-7 & 1.8 & 0-4 & 0.6 & p<0.05\end{array}$

N.S*

Post-reduction film:

Unacceptable

Acceptable

Good/anatomical

20

4

12

*N.S.: not significant.

The operators in the trial were experienced, so it is probable that less experienced staff would have had more difficulty reducing fractures with poor muscle relaxation (Group A).

\section{CONCLUSION}

The addition of Atracurium to Prilocaine for Bier's Blocks has been demonstrated to be safe in clinical practice (in view of its short-half life in the circulation,it is to be preferred to other muscle relaxants). However, degradation of this drug does not occur in the ischaemic limb and it remains active until the cuff is released.

This form of analgesia for the reduction of wrist fractures is of use in a minority of cases, such as heavily built adults with significant displacement at the fracture site. When Prilocaine alone is used for a Bier's Block in such cases it may fail, as was demonstrated in our study. 
Table 4 Suggested dosage for upper limb Bier's Blocks (Torda \& Klonymus, 1967)

\begin{tabular}{lc}
\hline Muscle relaxant & Dose $(\mathrm{mg})$ \\
\hline Tubocurarine & 1 \\
Gallamine & 10 \\
Succinylcholine & 4 \\
Decamethonium & $0 \cdot 2$ \\
(Atracurium & 2 ) \\
\hline
\end{tabular}

\section{ACKNOWLEDGEMENTS}

The authors' thanks to the Wellcome Foundation Ltd for their assistance and to Dr M. Popple and Dr W. Hamer for their help as volunteers.

\section{REFERENCES}

Alegesan K. (1983). Unwanted isolated limb. Anaesthesia 38, 1230-1.

Hughes R. \& Chapple D. (1981) The pharmacology of atracurium: a new competitive neuromuscular blocking agent. British fournal of Anaesthesia 53, 31-43.

Prippenau G. (985). The addition of muscle relaxants to intravenous regional anaesthesia. Regionalanaesthesie 8, 15-20.

Suppan P. (1983) Use of atracurium in the presence of lower or upper limb tourniquets. British fournal of Anaesthesia 55, 931-2.

Torda T. \& Klonymus D. (1967) The regional use of muscle relaxants. Archives of Surgery 94, 199-201.

Wilson D. H. \& Flowers M. (1986) $A$ \& $E$ Handbook. Butterworth, London. 